\title{
TiN and Boride Layers Obtained by Dehydrated Paste-Pack Boriding and PVD Treatments Formed on AISI M2 Steel
}

\author{
OA Gómez-Vagas ${ }^{1}$, M Ortiz-Domínguez ${ }^{2 *}$, A Cruz-Avilés ${ }^{2}$, I Morgado-González $^{2}$, J Solis-Romero ${ }^{1}$, VA \\ Castellanos-Escamilla ${ }^{1}$, E Coronel-Guerra ${ }^{1}$ and E Cardoso-Legorreta ${ }^{1}$ \\ 1. Research and Postgraduate Division, Instituto Tecnológico de Tlalnepantla, EdoMéx, México. \\ 2. Department of Mechanical Engineering, Universidad Autónoma del Estado de Hidalgo-Campus \\ Sahagún, Hidalgo, México. \\ * Corresponding author: martin_ortiz@uaeh.edu.mx.edu
}

Wear and corrosion are major causes of machinery downtime and material loss in industry contributing to decreased profits. Increase in material hardness is a common way to achieve improved wear resistance but leads to a loss in impact strength and can be very costly. Since wear is a surface phenomenon, the use of hard coatings can be an efficient solution, allowing the substrate to maintain its impact resistance and the coating can be produced to withstand wear, corrosion, abrasions and thermal loads while at the same time reducing costs by using diminutive amounts of hard materials [1]. A proposed solution consist of developing a hard, dense, wear- and corrosion-resistant coating formed on a surface with certain affinity in fracture toughness, as well as the creation of a dislocation interface that prevents the propagation of the corrosive medium to the substrate and the propagation of micro-cracks [2-3]. In particular, boriding is a recognized surface treatment for achieving high surface hardness (up to $2000 \mathrm{HV}$ ) and low coefficient of friction while improving the corrosion and erosion resistance and is being increasingly used in many industrial applications. Likewise, the hard TiN (Titanium Nitride) coatings are also used for coating machine tools such as drills, lathe tool inserts, stamps and punches, and expensive forming tools such as injection molds for plastics. In the present study, the microstructure of three coating configurations (TiN, $\mathrm{FeB}$, and $\mathrm{Fe}_{2} \mathrm{~B}$ ) formed on an AISI M2 surface have been investigated at different temperatures by dehydrated paste-pack boriding and reactive PVD treatments. Moreover, the addition of a TiN coating on the boride layer is seen as a possibility of reduction in the rate of crack propagation. The material involved in the research, is the AISI M2 high speed steel produced by powder metallurgy. The boriding and PVD treatments were carried out in two stages: boriding and then PVD. The samples were embedded in a closed in a closed cylindrical case (AISI 316L stainless steel) having a dehydrated paste of boron powder mixture inside with an average particle size of $10 \mu \mathrm{m}$ (see Figure 1). Boriding mixture contains of $\mathrm{B}_{4} \mathrm{C}$ (active source of boron), $\mathrm{Na}_{3} \mathrm{AlF}_{6}$ (activator), $\mathrm{SiC}$ (inert filler), and $\mathrm{SiC}_{8} \mathrm{H}_{20} \mathrm{O}_{4}$ which is used to protect surfaces. The boriding process was carried out in a conventional furnace under a pure argon atmosphere at 1223 and $1273 \mathrm{~K}$ for $6 \mathrm{~h}$ of exposure for each temperature. Once the boriding treatment was finished the container was removed from the furnace and slowly cooled to room temperature. In the second step, the pre-boriding iron samples were cleaned using sputtering etching with $650 \mathrm{~V}, 240 \mathrm{kHz}, 1600 \mathrm{~ns}$ for $15 \mathrm{~min}$. The TiN coatings were obtained by using a target with high power impulse magnetron sputtering (HIPIMS) with $2000 \mathrm{~W}, 500 \mathrm{~Hz}, 200 \mathrm{~ns}$ and three targets with direct current magnetron sputtering (DCMS) with $2500 \mathrm{~W}$ on each (see Figure 2). The sputtering targets were $\mathrm{Ti}(>99.8 \%)$. Interlayers of pure Ti were deposited with $400 \mathrm{~V}$ bias-voltage on all substrates. TiN layers were deposited by using bias-voltages of $75 \mathrm{~V}$ and $150 \mathrm{~V}$. The TiN layers had thicknesses of approximately $1 \mu \mathrm{m}$ and $2 \mu \mathrm{m}$. The coatings were deposited at $450^{\circ} \mathrm{C}$ with an Nitrogen/Argon (99.97\% pure) atmosphere $\left(A r: \mathrm{N}_{2}\right.$ Ratio $\left.=24: 5\right)$ and total pressure of $350 \mathrm{mPa}$ and 120 min of exposure time. The hard samples were grinded with $\mathrm{SiC}$ abrasive paper up to grit 2500. Afterwards, the samples were polished using a diamond suspension with particle size of $6 \mu \mathrm{m}$, finishing 
with particle size of $3 \mu \mathrm{m}$. The depth of the surface coatings and morphology were analysed by SEM and EDS (JEOL JSM-6360 LV at $20 \mathrm{kV}$ ). Figure 3 shows the cross-sections and the EDS analysis obtained by SEM at the TiN/FeB/ $\mathrm{Fe}_{2} \mathrm{~B}$ interphases for the AISI M2 steel (see Figure 4). These results demonstrate that the formed the TiN-FeB-Fe 2 B top layer produced a hardness in the expected range, around $2500 \mathrm{HV}$, and no incompatibility with the supporting boride layer was observed. The duplex treatment proved to be effective in the production of high hardness and wear resistant layers. The boriding treatment is recognized to produce high performance coatings, but the TiN layer improved its properties even further.

\section{References:}

[1] JR Davis in "Surface Hardening of Steels: Understanding the Basics", $1^{\text {st }}$ ed. (ASM, Ohio) p. 213.

[2] M Flores, S Muhl and L Huerta, Surf. Coat. Technol. 200 (2005) p.1315-1319.

[3] JL Bernal et al., Microsc. Microanal. 24 (S1) (2018), p. 1102.

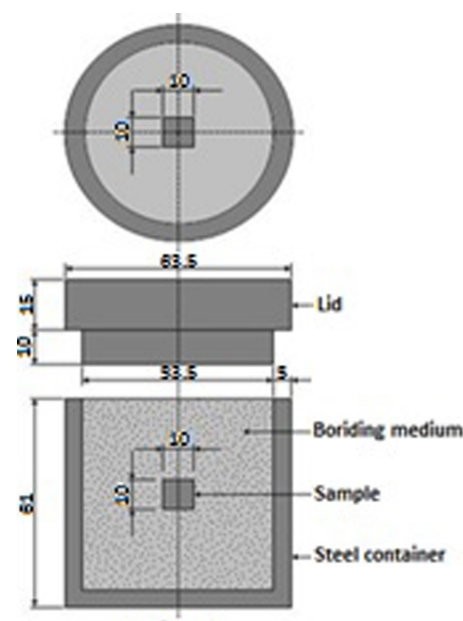

Fig. 1

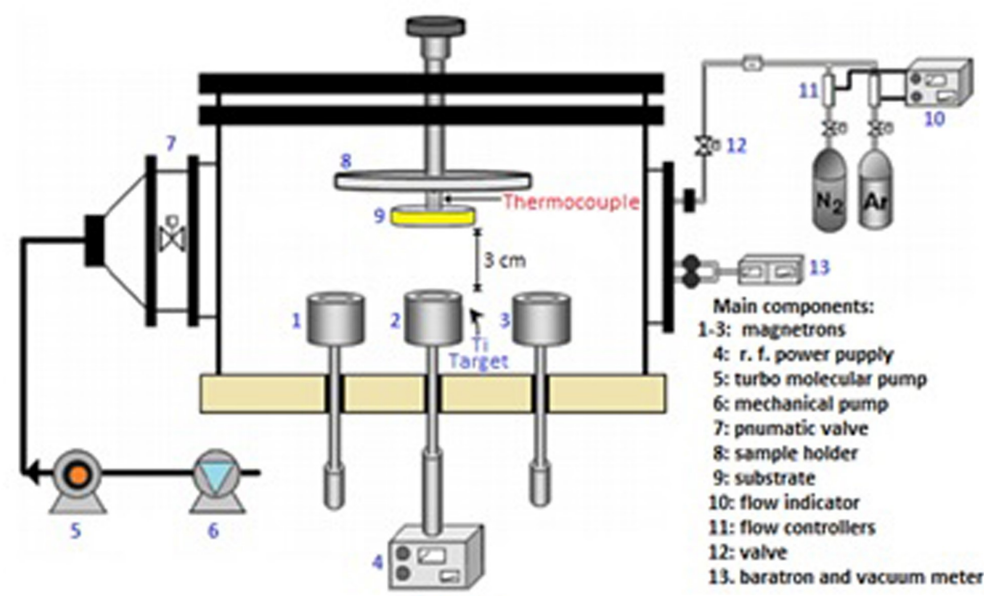

Fig. 2

Figure 1. Schematic view of the stainless steel AISI 316L container for the powder-pack boriding treatment and the schematic representation of the deposition reactor (Figure 2.).

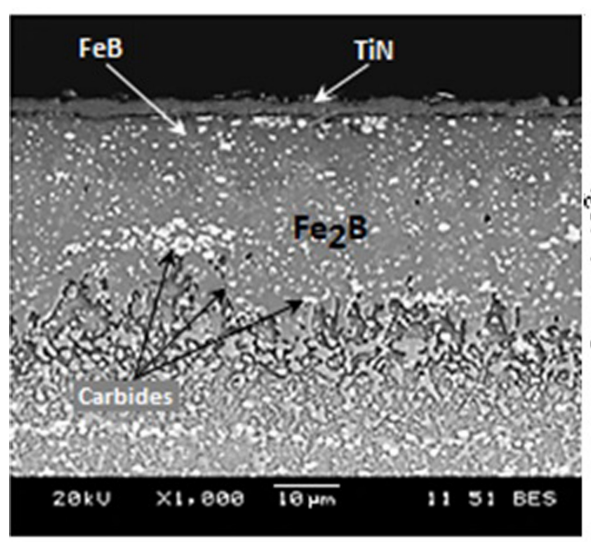

Fig. 3

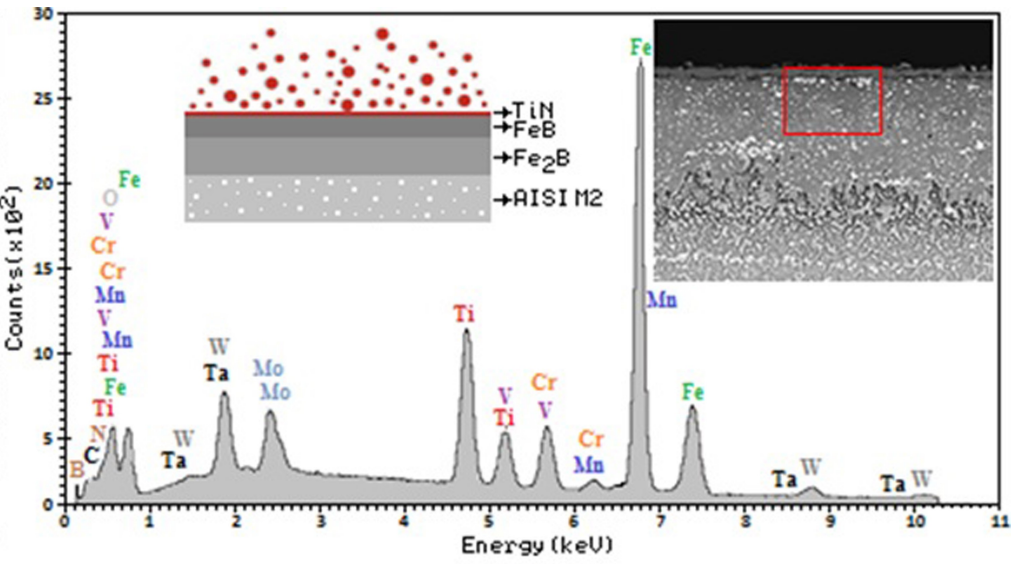

Fig. 4

Figure 3. Images (SEM) of cross-sections of borided: AISI M2 steel during 8 hours of treatment at 1223 $\mathrm{K}$ and $\mathrm{EDS}$ (Figure 4.) spectrum of the $\mathrm{TiN} / \mathrm{FeB} / \mathrm{Fe}_{2} \mathrm{~B}$ interphases for the AISI M2 steel. 